\title{
Optimization and Analysis of Hydrocarbon Recovery under Injection of Biopolymer, Synthetic Polymer and Gels in a Heterogeneous Reservoir
}

\author{
Dike Putra $^{1}$, Cenk Temizel ${ }^{2}$, \\ ${ }^{1}$ Rafflesia Energy \\ ${ }^{2}$ Aera Energy
}

\begin{abstract}
Water injection is a conventional method which increases the recovery percentage by providing pressure support and displacing oil in the heterogeneous porous medium. In such a displacement process, (low) mobility ratio is important for a more efficient oil displacement by the injected fluid. As such, the mobility ratio can be reduced using the fluids involving gelling agents for increasing in the volumetric sweep. While polymers degrade and break up on experiencing sudden shear stresses and high temperatures, polymer macromolecules are forced to flow into narrow channels and pores where molecular scission processes can take place. Thus, it is of utmost importance to have a strong understanding of the use of the right type and amount of viscosity as a reduction agent.

For polymer injection, a comparison of xanthan polymer and synthetic polymer mechanisms was conducted. A commercial full-physics reservoir simulator was coupled with a robust optimization and uncertainty tool to run the model, where a simplified gel kinetics was assumed to form a microgel with no redox catalyst. Water injection continues over all six layers for 450 days, followed by gel system injection for 150 days in the bottom two layers. Water injection was continued to four years. The top four layers have higher horizontal permeabilities, and a high permeability streak is at the bottom of the reservoir to reduce any helpful effects of gravity. Control and uncertainty variables were set to investigate the sensitivity of this process using the coupled optimization and uncertainty tool.

Results demonstrate deep penetration of gel and blocking of the high permeability bottom layers. Sensitivity studies indicate the relative merits of biopolymer, xanthan polymer in terms of viscosity effects vs synthetic PAM in terms of resistance factor vs in-situ gelation treatments and their crossflow dependence. Adsorption and retention of polymer and gel are permeability dependent.
\end{abstract}

Keywords: Biopolymer, Synthetic polymer, Gels, Cross-link, Heterogeneity, Optimization

Corresponding Author: dputra@rafflesiaenergy.com

\section{INTRODUCTION}

Waterflooding is predictable and likely succeed in a relatively homogeneous formation where fluid displacement as well as flood coverage may occur as expected. Various factors may adversely impact waterflood performance, especially in a heterogeneous reservoir. High permeability channels, low permeability streak, low transmissibility in certain zones, high storativity in spatial place and unidentified crossflow between layers commonly occur in heterogeneous formations. These could possibly lead to reduced sweep efficiency in waterflood operations.

A large bank of water moving uniformly as expected in an ideal waterflood operation is not observable. Instead, water moves in thin irregular streams, or fingers, toward the producing end. This phenomenon is known as viscous fingering. Displacement of a viscous oil by injected water in the porous medium will no longer be stable. The net effect of viscous fingering is a poor sweep and less oil recovery during waterflooding (Satter et al, 2008). The equation for overall waterflood recovery efficiency, $\mathrm{E}_{\mathrm{R}}$, is given by,

$$
E_{R}=E_{D} \times E_{V}
$$




$$
E_{V}=E_{A} \times E_{I}
$$

where,
$\mathrm{E}_{\mathrm{R}}=$ Overall recovery efficiency
$\mathrm{E}_{\mathrm{D}}=$ Displacement efficiency within the volume swept by water
$E_{V}=$ Volumetric sweep efficiency
$\mathrm{E}_{\mathrm{A}}=$ Areal sweep efficiency
$\mathrm{E}_{\mathrm{I}}=$ Vertical (or Invasion) sweep efficiency

The aim at EOR processes is to enhance the cumulative oil displacement efficiency. The overall efficiency depends on microscopic efficiency as well as macroscopic efficiency. The former refers to oil displacement at the pore scale. It measures the effectiveness of the displacing fluid in moving oil at those places in the rock where it meets oil. Macroscopic efficiency refers to the efficiency of displacement fluid(s) in contacting the reservoir in a volumetric sense. Also called conformance, it exhibits the effectiveness of a displacement fluid in sweeping out some volume of a reservoir, both areally and vertically, as well as how well the displacing fluid moves the displaced oil towards production wells (Green \& Willhite, 1998). Fig. 1 presents a schematic of sweep efficiencies; microscopic and macroscopic (areal sweep and vertical sweep).

Reservoir heterogeneity in a lateral direction, mobility ratio, pattern type as well as throughput determines the areal sweep efficiency. On the other hand, vertical sweep efficiency is mostly influenced by dissimilarities in layer permeability arising from varied depositional environment.

\section{RESERVOIR HETEROGENEITY}

The subsequent result of the physical reorganization and chemical reaction in the reservoir environment, such as compaction, dilation, solution, dolomitization, cementation, etc., will lead to further alteration of reservoir characterization. Generally, the heterogeneity of a reservoir depends on the depositional environment and subsequent events. The important thing to remember is that there is no such homogeneous reservoir in the world, and exists only varying degrees of heterogeneity.

The degree of reservoir heterogeneity is used to characterize a formation and predict the performance of a reservoir (Satter et al, 2008). Obviously, the reservoir may not be uniform in all intensive properties such as porosity, wettability, connate water saturation, and permeability. There are two critical types of heterogeneity in term of permeability, vertical and areal heterogeneities.

\section{VERTICAL HETEROGENEITY}

Interpreting fluid displacement behavior during secondary recovery and enhanced oil recovery is quite significant to define the proper permeability stratification of a pay zone. The uniformity coefficient represents the heterogeneity of formation from zero to one. Two famous methods widely used to describe vertical heterogeneities are, Dykstra-Parsons permeability variation (V) and Lorenz coefficient (L), which are described below. 

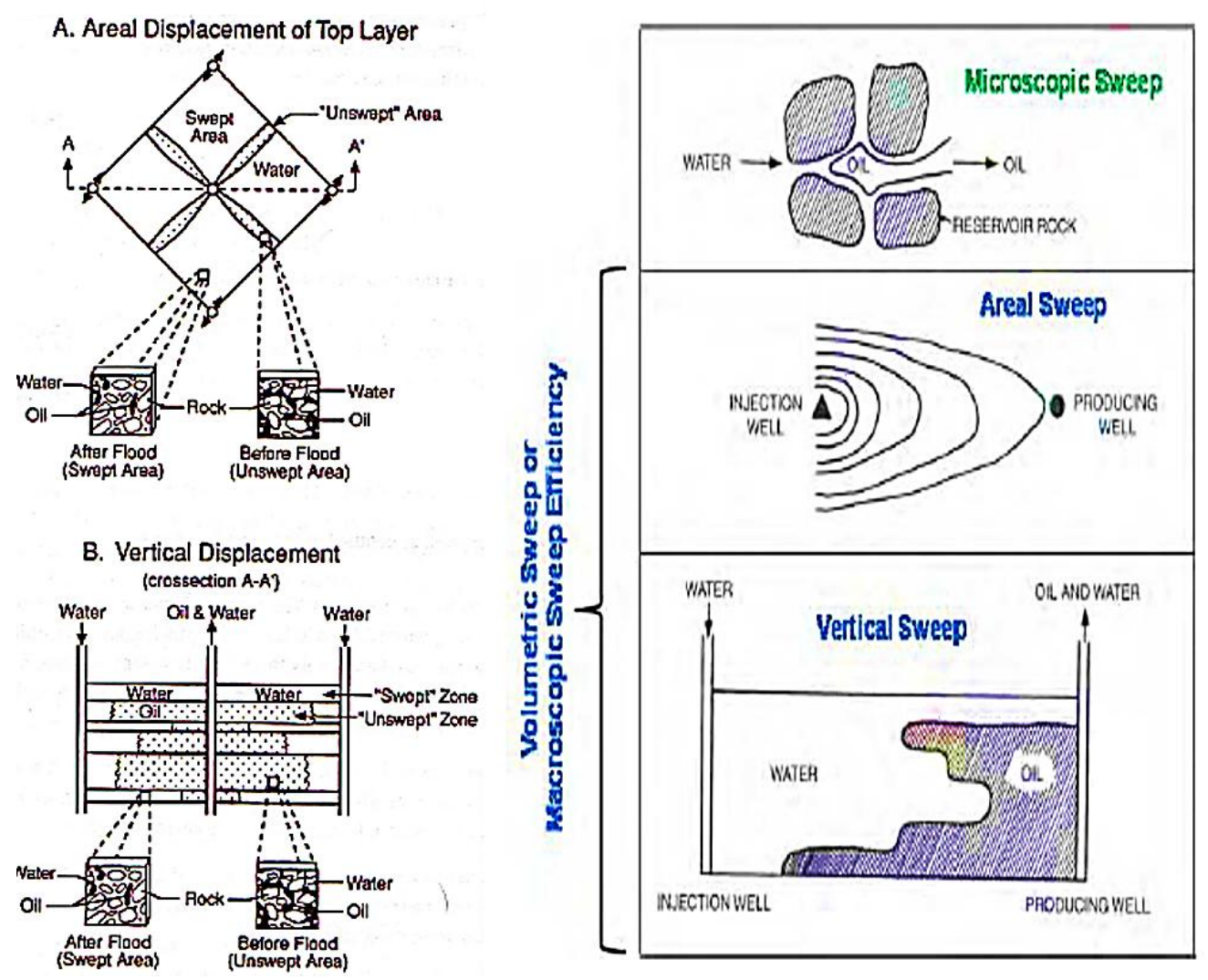

Figure 1 Areal and vertical of oil by waterflood (Shatter \& Thakur, 2008)

\section{Dykstra-Parsons permeability variation}

Dykstra and Parsons (1950) introduced the concept of permeability variation coefficient, V, which is a statistical measure of non-uniformity of a set of data (Ahmed, 2001). Normally, the set of data is acquired from core samples. This method is commonly referred to as Permeability Ordering Technique.

\section{Lorenz coefficient}

Schamlz and Rahme (1950) introduced a single parameter that describes the degree of heterogeneity within a pay zone section (Ahmed, 2001). The term is called Lorenz coefficient, L, which varies between zero and one. Area between diagonal and deviated points serve as the basis for determining value of Lorenz coefficient (Satter et al, 2008), and is given by,

$$
\text { Lorenz coefficient }=\frac{\text { Area enclosed by plot points and the diagonal }}{\text { Area enclosed by the diagonal and bottom right corner of the plot }}
$$

Warren and Price (1961) proposed the relationship between permeability variation, V, and Lorenz coefficient, L, for log-normal permeability distribution as shown in Fig. 2.

Another method of vertical heterogeneity is Crosslink Index, which is a measure of the degree of fluid communication anticipated between two adjacent layers in a stratified reservoir. The communication may range between non-communicating and fully communicating. Knowledge of the degree of communication between layers is vital in understanding the flow dynamics during fluid injection in this type of reservoir (Satter et al, 2008)[20]. 


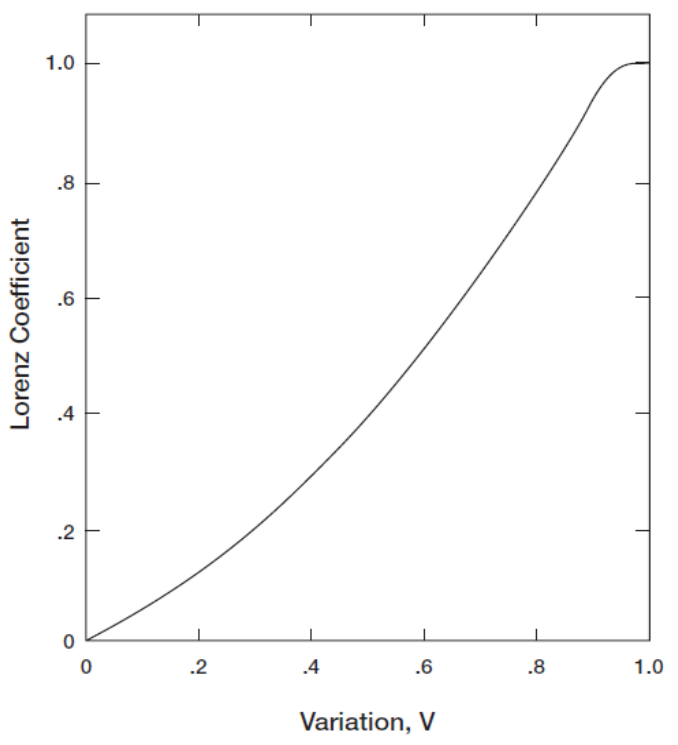

Figure 2 Correlation of Lorenz coefficient and permeability variation (Ahmed, 2001)

\section{AREAL HETEROGENEITY}

Similar to the case in the vertical direction, the lateral direction also has permeability variations. Fluid displacement depends on storage geometry such as structural shape and thickness of strata, and the local values of physical parameters characteristic to the porous rock such as transmissibility, reservoir permeability-thickness product $(\mathrm{kh})$ and porosity.

Several geostatistical approximation methods have been developed to accurately describe the spatial distribution of rock properties from point to point. These approaches involve interpolating among known data points and extrapolating beyond these known data values. They are usually called the regionalized variables.

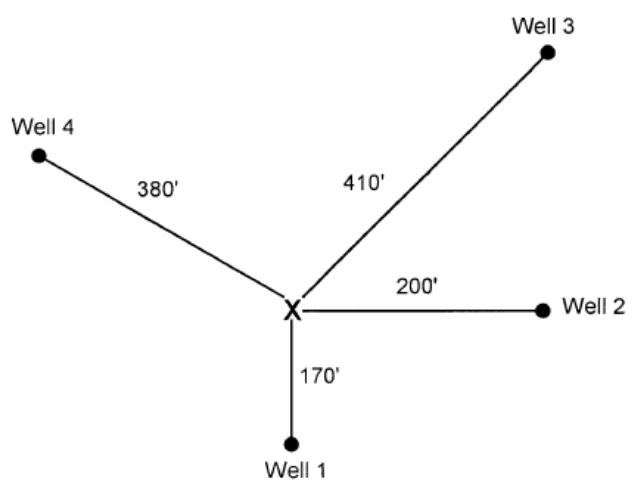

Figure 3 Well locations as points of spatial place (Ahmed, 2001)

To seize regionalized variables, an appropriate formulation should capture a double aspect of randomness and spatial correlation into account. The method uses the following expression,

$$
Z^{*}(x)=\sum_{i=1}^{n} \lambda_{i} Z\left(X_{i}\right)
$$


with

$$
\sum_{i=1}^{n} \lambda_{i}=1
$$

where;

$\mathrm{Z}^{*}(\mathrm{x})=$ estimate of the regionalized variable at location $\mathrm{x}$

$\mathrm{Z}\left(\mathrm{x}_{\mathrm{i}}\right)=$ measured value of the regionalized variable at position $\mathrm{x}_{\mathrm{i}}$

$\lambda_{\mathrm{i}}=$ weight factor

$\mathrm{n}=$ number of nearby data points

The simple conventional interpolation/extrapolation techniques are listed below (Ahmed, 2001)[18],

\section{Polygon Method}

This method is fundamentally based on assigning the nearest measured value of the regionalized variable to the designated location.

\section{Inverse Distance Method}

By inversing distance method, data points are weighted during interpolation such that the influences of one data point relative to another decline with distance from the desired location.

$$
\lambda_{i}=\left(\frac{1}{d_{i}}\right) / \sum_{i=1}^{n}\left(\frac{1}{d_{i}}\right)
$$

where;

$$
\begin{aligned}
& \mathrm{d}_{\mathrm{i}}=\text { distance between the measured value and location of interest } \\
& \mathrm{n}=\text { number of nearby points }
\end{aligned}
$$

\section{Inverse Distance Square Method}

This method assigns a weight to each measured regionalized variable by the inverse distance squared of the sample to the point being estimated.

$$
\lambda_{i}=\left(\frac{1}{d_{i}}\right)^{2} / \sum_{i=1}^{n}\left(\frac{1}{d_{i}}\right)^{2}
$$

It gives proportionately more weight to near wells than the previous approach.

\section{MOBILITY-CONTROL}

For waterfloods, mobility control is the ratio of the mobilities of water and oil. Mobility ratio, M, for a waterflood is given by,

$$
M=\frac{\text { Mobility }_{\text {water }}}{\text { Mobility }_{\text {oil }}}=\frac{\lambda_{w}}{\lambda_{o}}=\frac{k_{r w} / \mu_{w}}{k_{r o} / \mu_{o}}=\frac{k_{r w} \mu_{o}}{k_{r_{o}} \mu_{w}}
$$

Where, $\lambda_{\mathrm{w}}$ and $\lambda_{\mathrm{o}}$ are water and oil mobilities respectively, in $\mathrm{md} / \mathrm{cp} ; \mathrm{k}_{\mathrm{rw}}$ and $\mathrm{k}_{\mathrm{ro}}$ are relative permeabilities to water and oil respectively; $\mu_{\mathrm{o}}$ and $\mu_{\mathrm{w}}$ are oil and water viscosities, respectively (Lyons \& Plisga, 2005).

Volumetric sweep efficiency increases with decreasing $\mathrm{M}$, therefore mobility ratio is an indication of the stability of a displacement process with flow becoming unstable or when $\mathrm{M}>1.0$. Thus, a large viscosity 
contrast between the displacing fluid and the displaced fluid causes a large mobility ratio that promotes fingering of water by more viscous oil (Fig. 4). Thus, recovery efficiency is reduced. As such, mobility ratio can be reduced by increasing the viscosity of the injected water using polymeric viscosifying agents. Capillary number, $\mathrm{N}_{\mathrm{c}}$, is a dimensional group that gives the ratio of viscous to capillary (interfacial) forces as in the following,

$$
N_{c}=\frac{\text { viscous forces }}{\text { capillary forces }}=\frac{v \mu_{w}}{\sigma_{o w}}
$$

where $v$ is the interstitial velocity of the displacing fluid, $\mu_{\mathrm{w}}$ is its viscosity and $\sigma_{\mathrm{ow}}$ is the interfacial tension between oil and the displacing fluid. Capillary numbers for a mature waterflooding process are commonly in the order of $10^{-7}$ to $10^{-6}$ (Green \& Willhite, 1998). At the end of the waterflooding process, experience has shown that due to low capillary numbers a significant amount of oil is left behind in the reservoir trapped by capillary forces at the pore scale. Thus, if the capillary number is increased through the application of EOR processes, residual oil will be mobilized and recovered.

\section{Production well}

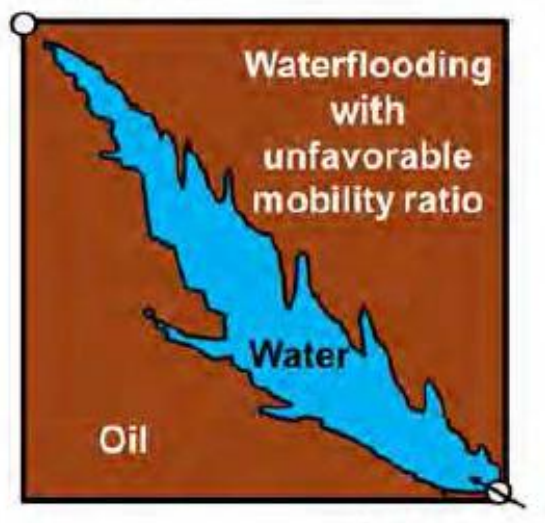

Injection well

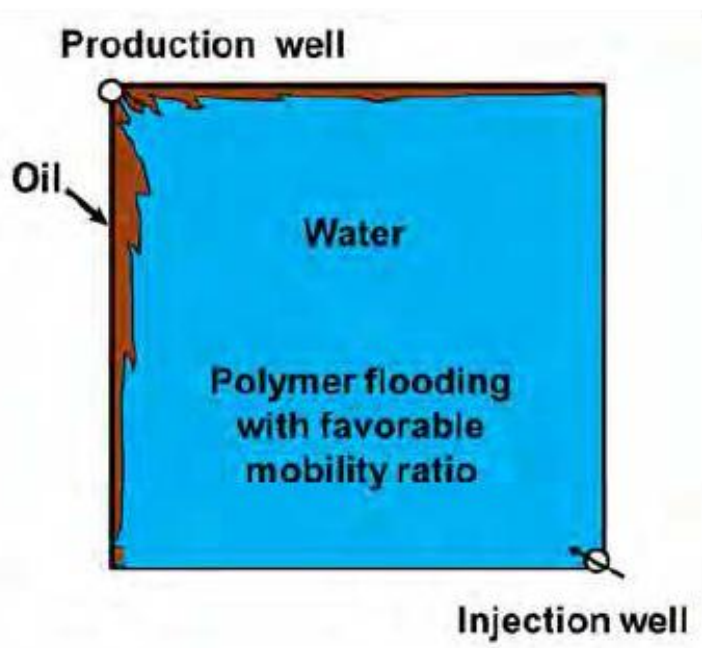

Injection well

Figure 4 (a) Waterflooding with unfavorable mobility ratio $(M>1)$, (b) Polymer augmented waterflooding with favorable mobility ratio $(M \leq 1)(($ Sydansk \& Romero-Zerón, 20111; Cenk et al.,2017)

\section{Polymer Flooding and Gel Treatment}

As global energy demand expands quickly and with lack of easy alternatives, hydrocarbon recovery becomes essential to increase petroleum sources. Since $60-80 \%$ of oil still stays in the petroleum reservoirs, it is important to design new methods and/or techniques to recover the stuck hydrocarbon in oil reservoirs. Enhanced Oil Recovery (EOR) techniques that include surfactants, polymers, and gas injection and gel treatments, have been studied and used over forty years. EOR methods aid for hydrocarbon recovery that cannot be removed by natural or oil lifts (primary recovery) or water injection alone. EOR techniques increase oil recovery with another 5-30\% of hydrocarbon recovery. Polymer flooding and gel treatment are the most common EOR techniques due to reasonable recovery rates and suitable application.

Polymer flooding was initially used in 1960 s to reduce the mobility mismatch of oil and aqueous phase. Polymers are classified as synthetic polymers and biopolymers. Synthetic polymers are synthesized while biopolymers are produced by microorganisms including bacteria and fungi, and living organisms including algae and leaves of plants. Polymers have adjustable conformation in aqueous 
solutions due to their viscoelastic behaviors. Both synthetic polymers and biopolymers have been applied for polymer flooding. Gels are obtained by either a synthetic polymer or biopolymer. Gel treatment contains higher polymer viscosity than polymer flooding and is a promising method for hydrocarbon recovery.

\section{Mechanism of Polymer Flooding and Gel Treatment}

The underlying principle of EOR techniques is to increase viscosity of injected water. Increased water flow viscosity develops a way to give stuck oil, sweep ability. Additionally, the increased water viscosity minimizes water fingering or permeability. Therefore, hydrocarbon recovery takes place easily with polymer addition into water injection. Simply, the mobility ratio (M) is calculated by eq. (5) as shown in the previous section. Oil sweep ability increases when the oil and the injected aqueous part has similar mobility. Hydrocarbon recovery rises if mobility ratio is around one. When mobility ratio is higher than one, the injected polymer or gel viscosity should be increased to raise oil recovery. Thus, mobility ratio formula is used to calculate required water viscosity and permeability for better oil recovery.

\section{COMMONLY USED IN POLYMER FLOODING AND GELS Synthetic Polymers}

The source of synthetic polymers is mostly from petroleum, oil, corn canes and derivatives. Synthetic polymers are polymerized from their monomers in small-scale or large-scale reactors. Acrylamide and its derivatives have been widely used for oil recovery purposes. Polyacrylamide, partially hydrolyzed polyacrylamide, and salinity-tolerant polyacrylamide synthetic polymers have been applied as chemical EOR additives.

Polyacrylamide (PAM), was the first polymer that was used for oil recovery. The structure of polyacrylamide monomer, $\left(\mathrm{C}_{3} \mathrm{H}_{5} \mathrm{NO}\right)_{\mathrm{n}}$, is shown in Fig. 5. PAM is used as a model polymer in EOR studies with a high molecular weight. The high molecular weight of PAM is used due to its chemically, mechanically and thermally sensitive degradation properties. As synthetic polymer synthesis can be modified, less chemical, mechanical and thermally sensitive polyacrylamide derivatives are produced.

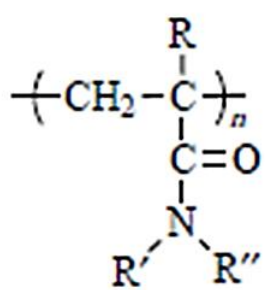

$$
\text { Polyacrylamide (PAM) }\left(R, R^{\prime}, R^{\prime \prime}=H\right)
$$

Figure 5 Repeating unit of polyacrylamide (kirk-othmers, 2013)

Hydrolyzed polyacrylamide HPAM, is the most commonly used polymer in the field. The repeating unit of HPAM copolymer contains acrylamide and acrylic acid, which are shown in Fig. 6. HPAM is a costeffective polymer and is resistant to bacterial digestion. In addition to these advantages, it can also be used at high mechanical forces. However, HPAM's viscosity reduces at high temperatures or high salinity. The reduced viscosity causes less oil sweep efficiency and less oil recovery. 


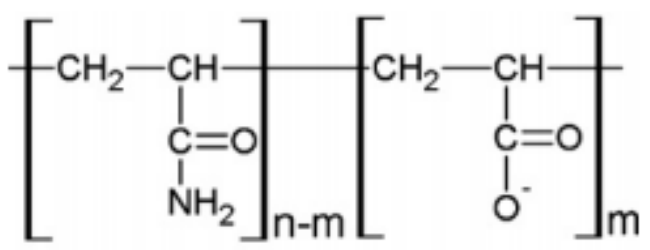

Figure 6 Monomer of HPAM (Yegin et al, 2017)

KYPAM, salinity tolerant polyacrylamide is shown in Fig. 7. $R_{1}, R_{2}, R_{3}$ and $R_{4}$ can be various carbon subunits $\left(\mathrm{C}_{1}-\mathrm{C}_{12}\right)$ or hydrogen. KYPAM is a salt-resistant polymer branched polymer. Increased carbon number of $\mathrm{R}_{4}$ illustrates higher salinity resistance property of KYPAM. It is well-known that same molecular weight branched hydrocarbon chain has better stability than unbranched one. Thus, KYPAM with more branched structure has better shear resistance ability, temperature and salt resistant properties than HPAM.

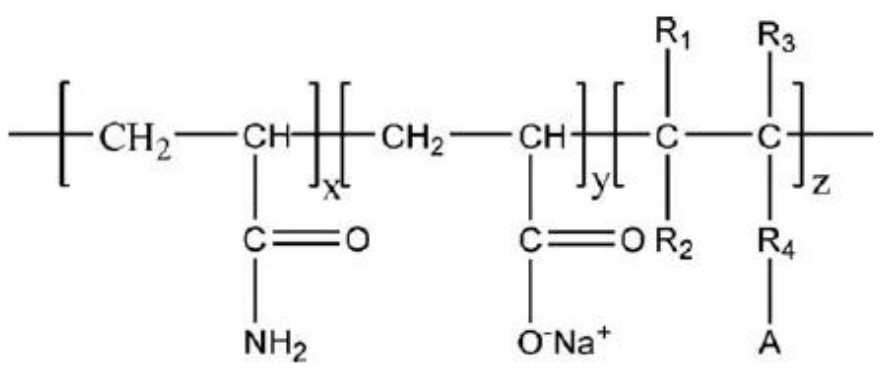

Figure 7 KYPAM chemical structure (Wever et al, 2013)

\section{Biopolymers}

The origin of biopolymers is either from biomass or living organisms and microorganisms. Biopolymers are known as eco-friendly, non-toxic and renewable polymers. Hence, biopolymers are used for polymer flooding to increase oil sweep efficiency. Biopolymers are produced in fermenters, either large-scale or small-scale. Xanthan gum is the most commonly used biopolymer in the field. However, it is not as common as HPAM. Xanthan gum and scleroglucon biopolymers have been applied in EOR and are described below.

Xanthan gum is synthesized by Xanthomonas campestris bacteria. Xanthan gum has been commercially available for over 50 years. The combination of mannose, glucuronic acid and glucose monosaccharides is the repeating unit of Xanthan gum as shown in Fig. 8. Molecular weight of Xanthan gum varies between 2000-50000 kDa. It shows better shear stress resistance, salinity tolerance and thermal stability than HPAM. Xanthan gum is stable over two years at $80{ }^{\circ} \mathrm{C}$. However, it is not resistant to bacterial digestion or degradation as a poly-hydro-alkanote biodegradable polymer. Furthermore, Xanthan gum is expensive and its injection is not easy. 


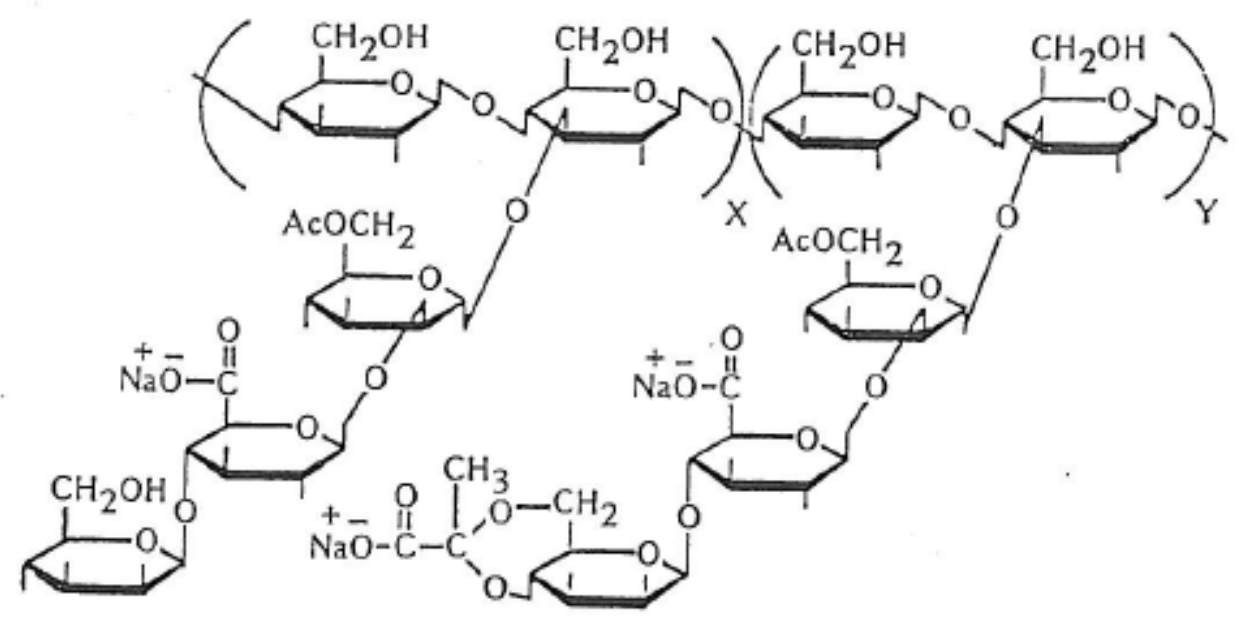

Figure 8 Structure of Xanthan Gum (Surtek, 2010)

Scleroglucon is generated by Sclerotium Rolfsii fungus. Four glucose monosaccharides unit, which is shown in Fig. 9, is the repeating unit of Scleroglucon. It is a larger biopolymer than Xanthan gum with a molecular weight of 200-6000 kDa. It displays preferable resistance to high salinity and shear stress compared to Xanthan gum. It is also stable thermally $\left(\sim 90{ }^{\circ} \mathrm{C}\right)$ and in different $\mathrm{pH}$. Nonetheless, scleroglucon is the most expensive polymer in EOR technology. It is not resistant to bacterial degradation since it is a biodegradable exopolysaccharide.

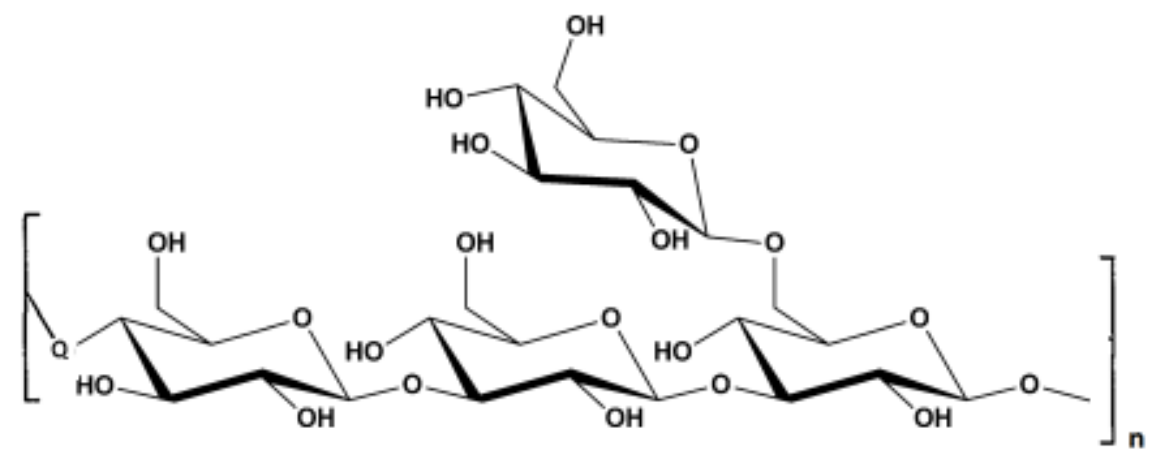

Figure 9 Chemical structure of Scleroglucon (Schmid et al)

\section{Gels}

Gel treatment is an effective EOR technique to increase oil recovery. Gel treatment suggestion has been studied for over 25 years. Especially in heterogeneous and/or at high permeable reservoirs, polymer gels are preferred. Gel treatment aids to heterogeneous reservoirs to form homogenous spaces. Oil based gels reduce oil permeability. Similarly, water based gels and hydrogels minimize water phase permeability. Gel treatment is also used before an expensive polymer injection to reduce permeability of desired part.

In gel treatment, lower concentration gels are injected in the first stage. This way, the injected gel reaches further away with its lower viscosity property. Similarly, this leads the gel to block lower pressure 
drop. In the last stage, higher concentration gel is injected. Therefore, the injected gel resists higher differential pressure.

Polymer gels have higher viscosity than the injected polymers. This causes oil to mobilize, or increase oil mobility. Commercially available microgels, such as performed particle gel (PPG), stimuli sensitive (e.g. temperature, $\mathrm{pH}$ ) polymer gels, can be used for oil recovery. Generally, salinity, $\mathrm{pH}$, temperature and shear stress are important parameters for structure of gels (e.g. swell, shrink, stability). For instance, gel formation is less possible at acidic $\mathrm{pH}$ whereas gelation time is quick.

\section{Comparison of polymers}

Synthetic polymers have been used in pharmaceutical applications, such as, drug nanocarriers and biomedicine. They have also been used in biomedical applications, such as, bone regeneration, medical devices including orthopedic implants, cardiovascular devices, and implantable drug delivery due to biocompatibility of synthetic polymers. Kevlar fibers, one type of synthetic polyamides, have been used in protective gear due to their strength of chemical bonds. Synthetic polymers are also used in antibacterial and/or antifouling in wide fields. Polyacrylamide or PAM, a common synthetic polymer, has been used in helicopter landing pads, wind and water erosion control as soil stabilizer additive due to its environment friendly behavior. The addition of water soluble synthetic polymers to the flooding water in oil reservoirs raises reservoir sweep that leads oil displacement. Thus, injection of synthetic polymers has also thickened water to improve mobilization of oil.

Most synthetic polymers are made from materials originally from petrochemicals, natural gas, crude oil, coal, and sugar or corn cane. Synthetic polymers are synthesized in industrial reactors from their monomers by polymerization reaction. Some synthetic polymers or water-soluble polymers behave like emulsions in drilling fluids. Thus, the oil production enlarges based on the improved sweep property of the oil reservoir. Acrylamide is a vinyl or acrylic monomer which has been widely used in oil recovery. Polyacrylamide, PAM, was the first polymer that has been used to thicken water. PAM, partially hydrolyzed polyacrylamide (HPAM), vinyl ether copolymer, polyvinyl pyrrolidone, polyethylene oxide, $\mathrm{N}$-vinyl-2-pyrrolidone (NVP) have been used as synthetic polymers in oil recovery systems.

Among the kinds of synthetic polymers, HPAM is the most common injected polymer in oil recovery process because of its cost effectiveness, its resistance to bacterial digestion and a low concentration of HPAM could give higher viscosity. However, HPAM loses its viscosity at high temperature, high salinity or high hardness. Additionally, the chains of HPAM could degrade at high shear rates. Thus, HPAM is not suitable at high temperature, high salinity, high shear stress and high hardness regions. While KYPAM, as mentioned in the previous section, has better resistance to salinity, shear stresses and high temperatures compared with HPAM and could be used to relative higher salinity, higher shear stress and higher temperature regions.

Biopolymers have been studied in various applications including biomedical, geotechnical, environmental and so on. They are being used as nanocarriers to cure cancer and tumor cells. Furthermore, they can be used in therapeutic aids, medicines, drug delivery, wound closure, coatings, food containers, agriculture clothing, and packing materials. Biopolymers are environment friendly due to the fact that they are produced from agricultural and biomass waste. Therefore, biopolymers are renewable, non-toxic and biocompatible. Due to the low toxicity of biopolymers, they have been also applied for wastewater treatment, waste encapsulation. Biopolymers have been also used in drilling, polymer-augmented water flooding and chemical flooding. Biopolymers increase viscosity of the water that assists sweep efficiency for EOR processes. Biopolymers as drilling fluids help to increase plug 
formation for EOR methods. They can be applied for selective plugging of high permeable places so water can flow to the oil rich places in the reservoirs for effective oil recovery.

Biopolymers are the polymers produced from agro-sources, bio-based monomers or fossil based biodegradable polymers. They are classified with their origins as bio-based or synthetic. The origin of bio-based biopolymers is either from microorganisms by fermentation or renewable raw materials of plants and animals. Synthetic biopolymers are produced from corn, sugar, starch, etc. Agro-resource biopolymers are polysaccharides, cellulose, starch, chitin, chitosan, and alginates. Fermentation from microorganism biopolymers are polyhydroxyalkanoates, such as, polyhydroxybutyrate. Chemically synthesized biopolymers are polylactides (PLA), polybutadiene succinate, polyethylene (PE), polytrimethylene terephthalate, and poly-p-phenylene. Xanthan gum, guar gum, hydroxyethlcellulose, hydroxypropylguar, scleroglucan and sodium carboxymethylcellulose biopolymers have been used in the oil recovery processes.

Xanthan gum, which has been fermented and become commercially available for long time, is the commonly used biopolymer in EOR because of its suitable viscosity, shear resistance, temperature and salt tolerance properties. Compared with synthetic polymers, such as, HPAM, Xanthan gum has high salt, temperature and shear resistance. Thus, it is used at high salt or temperature or shear stress conditions where HPAM could not be used. Because of its low toxicity, it is environmental-friendly as well. However, it is expensive and degrades by bacteria. Additionally, it has some injection problems. Those drawbacks limit its application especially when HPAM works acceptably. Scleroglucon, another biopolymer, shows more resistance than Xanthan gum in salt existence and different $\mathrm{pH}$ and shear stress. However, it is very expensive; thus, it is not economical like Xanthan and limits its use in EOR.

Gels, formed by biopolymers and/or synthetic polymers, are widely used in many industries. Gels have been used in many fields, such as, tissue engineering, medical, pharmaceutical, personal care and so on. Gels could be used as scaffolds in tissue engineering. Environmentally sensitive gels and gels that are responsive to specific molecules are used as sensors. Gels are also used in drug delivery and therapy systems, such as, sustained-release drug delivery, rectal drug delivery, cancer therapy and so on. Also, gels have been used in disposable diaper, contact lenses and breast implants as well. They have been used in different types of glue as well.

The idea of using gels for oil recovery had started in the 1990s. Movable gels have higher viscosity compared to biopolymers and synthetic polymers, and thus have increased oil mobility. They can reduce permeability. Therefore, gels have been used in highly permeable reservoirs. Additionally, gel injection could be preferred rather than polymer injection in heterogeneous reservoirs, where gels could make the reservoirs homogenous. Gels injection can be preferable due to its increment of sweep efficiency before injecting an expensive polymer. The disadvantage of gel injection is that an additional gel formation process is required and thus it increases the process cost.

\section{Simulation Model and Sensitivity Runs}

This test problem describes in-situ gelation of a stratified reservoir based on the approach of Scott et al (SPEJ, Nov 1987).

Sensitivity studies indicate the relative merits of biopolymer xanthan polymer (viscosity effects) vs synthetic PAM (resistance factor) vs insitu gellation treatments and their crossflow dependence.

The models has isotherm temperature reservoir. Xanthan has correlation for non-linear viscosity mixing, the rest are linier and stable. For gel cases, the reaction between xlinker and Xanthan yield a 
gelatin system. The mass balance of reaction is depend on reactant and product coefficient. A simplified gel kinetics is assumed to form a microgel with no redox catalyst and ignoring degradation. The concentration of PAM and Xanthan are modified to have molecular weight up $10000 \mathrm{lb} / \mathrm{lbmole}$. This is the maximum of molecular weight of polymer according to Seright (1997).

The reservoir grid is a 20x1x6 cross-section with one injector and one producer completed through all 6 layers. The top four layers have higher horizontal permeabilities, and a high-permeability streak is at the bottom of the reservoir to reduce any helpful effects of gravity. The injection scheme has water injection over all 6 layers for 450 days, followed by gel system injection for 150 days in the bottom 2 layers. Water injection is continued to 4 years. Results demonstrate deep penetration of gel and blocking of the high permeability bottom layers. This can be seen by the large pressure increase around the injector at 600 days, redirection of injected water and the decrease in produced WOR at 900 days.

Special features include;

- Chemical reaction modeling of gelation process (assumes gel effects only plugging but not viscosity).

- Adsorption /retention of polymer and gel which are permeability (region) dependent.

- Permeability reduction of polymer/gel (RRF), which is again region dependent.

- Sensitivity studies can also be conducted comparing the effectiveness of gel and simple polymer treatments.

- For simple polymer injection, a comparison of xanthan (bio) polymer and PAM (synthetic) polymer mechanisms can be conducted.

- This dataset uses a mass fraction version of concentrations (*MASSBASIS)

Table 1 Input components

\begin{tabular}{ccccccc}
\hline & Component & Aqueous & Gaseous & Solid & $\mathbf{T}_{\mathbf{c}}(\mathbf{F})$ & $\begin{array}{c}\text { MW } \\
\text { (lb/lbmole) }\end{array}$ \\
\hline $\mathbf{1}$ & WATER & Reference phase & $\begin{array}{l}\text { K-value } \\
\text { partition }\end{array}$ & - & 647.4 & 18 \\
\hline $\mathbf{2}$ & XLINKER & Reference phase & $\begin{array}{l}\text { K-value } \\
\text { partition }\end{array}$ & - & 0 & 206 \\
\hline $\mathbf{3}$ & XANTHAN & Reference phase & $\begin{array}{l}\text { K-value } \\
\text { partition }\end{array}$ & Adsorbed & 0 & 10000 \\
\hline $\mathbf{4}$ & POLYMER & Reference phase & $\begin{array}{l}\text { K-value } \\
\text { partition }\end{array}$ & Adsorbed & 0 & 10000 \\
\hline $\mathbf{5}$ & PREGEL & Reference phase & $\begin{array}{l}\text { K-value } \\
\text { partition }\end{array}$ & Adsorbed & 0 & 10206 \\
\hline $\mathbf{6}$ & DEAD_OIL & Reference phase & $\begin{array}{l}\text { K-value } \\
\text { partition }\end{array}$ & - & 0 & 100 \\
\hline
\end{tabular}

Table 2 Input parameters

\begin{tabular}{|c|c|c|c|c|c|c|}
\hline Item & Units & WATER & XLINKER & XANTHAN & PREGEL & DEAD_OIL \\
\hline & & Aqueous & Aqueous & Aqueous & Aqueous & Oleic \\
\hline
\end{tabular}


Dike Putra/JEEE Vol. 02 No.02/2018

\begin{tabular}{lllllll}
\hline Options & & User Input & User Input & User Input & User Input & User Input \\
\hline AVISC & $\mathrm{cP}$ & 0.5 & 0.5 & 4 & 0.5 & 1
\end{tabular}

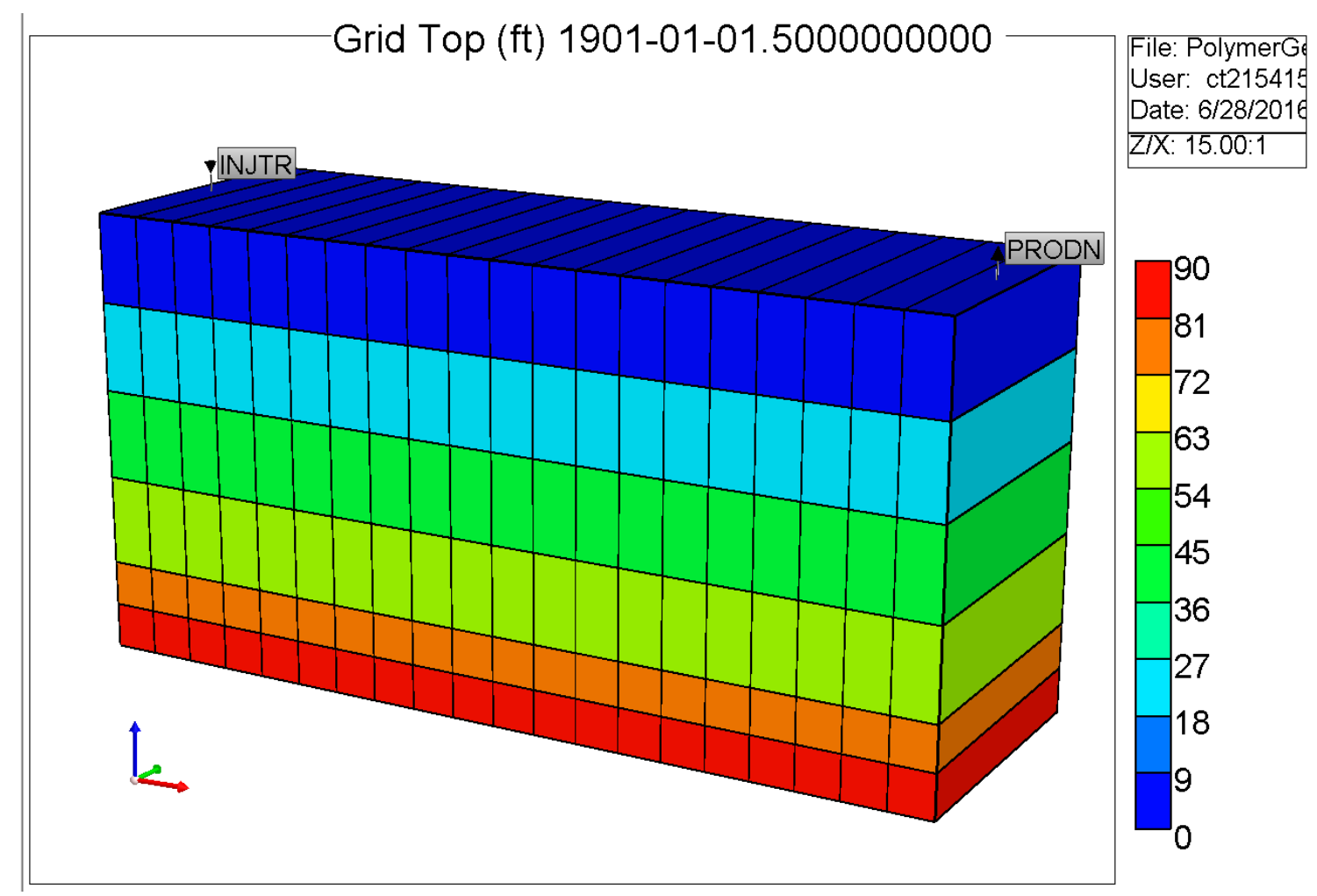

Figure 10 Reservoir simulation grid 
Dike Putra/JEEE Vol. 07 No.01/2018

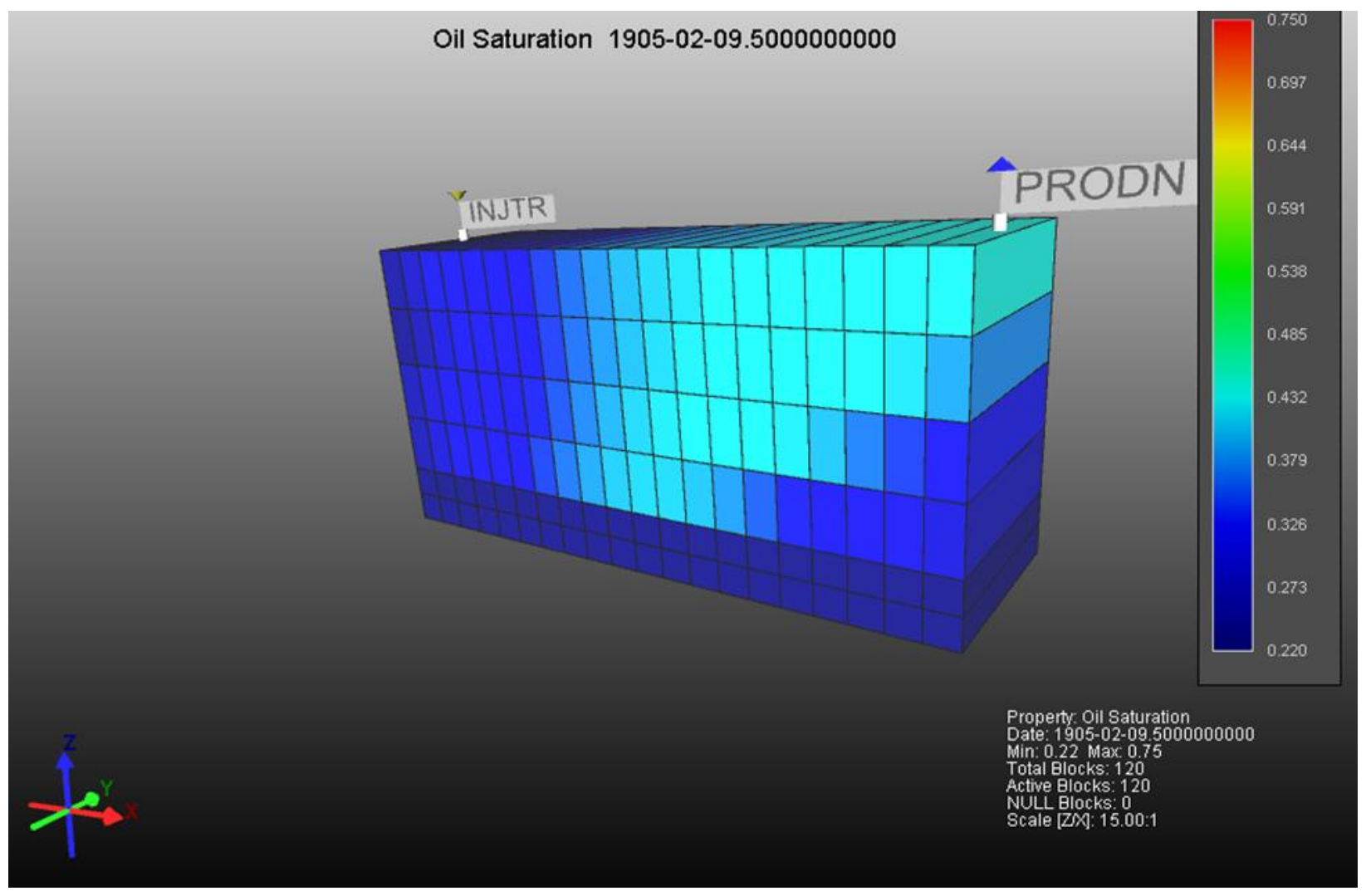

Figure 11 Oil Saturation - Gel Model (Final)

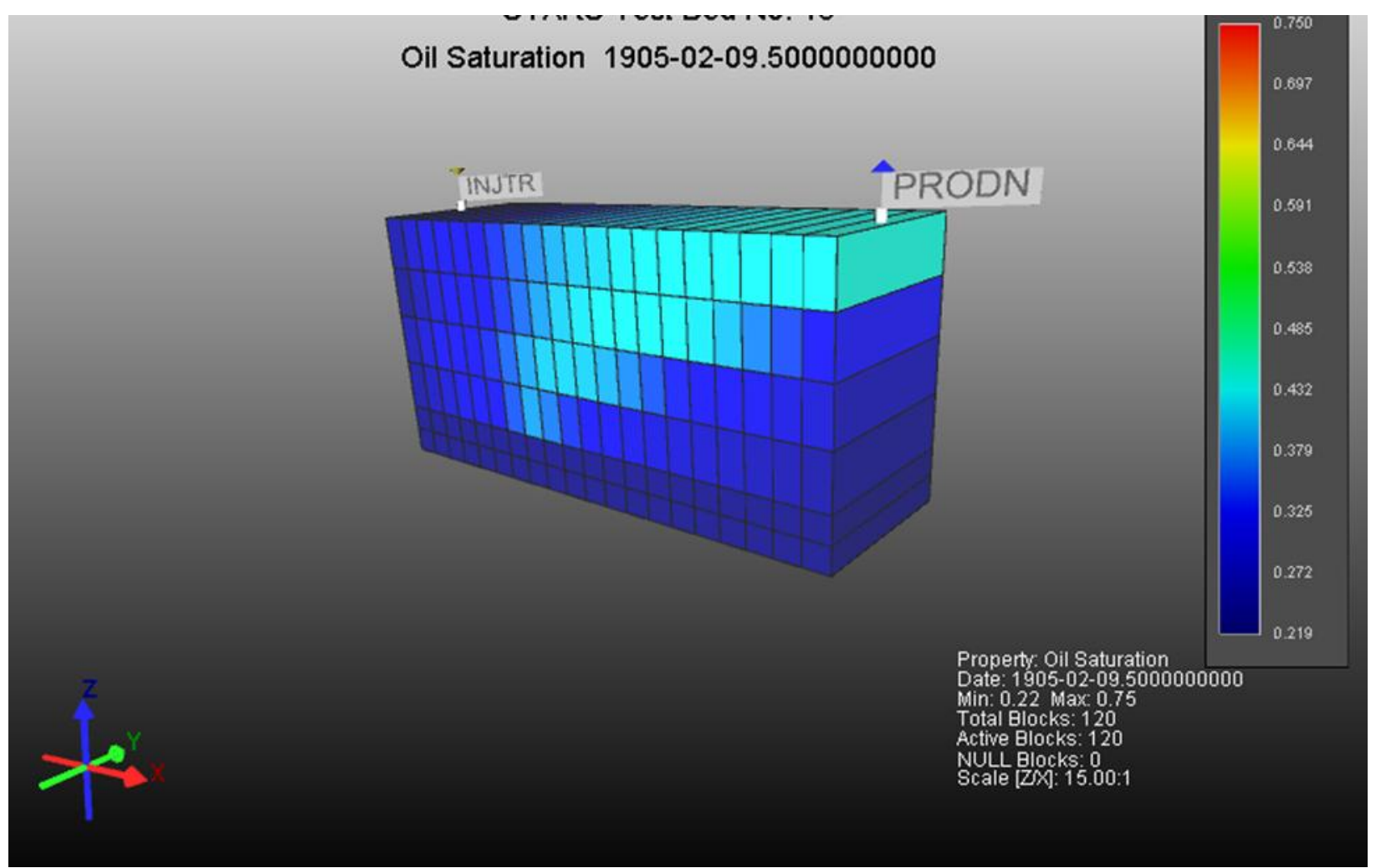


Figure 12 Oil Saturation - PAM Model (Final)

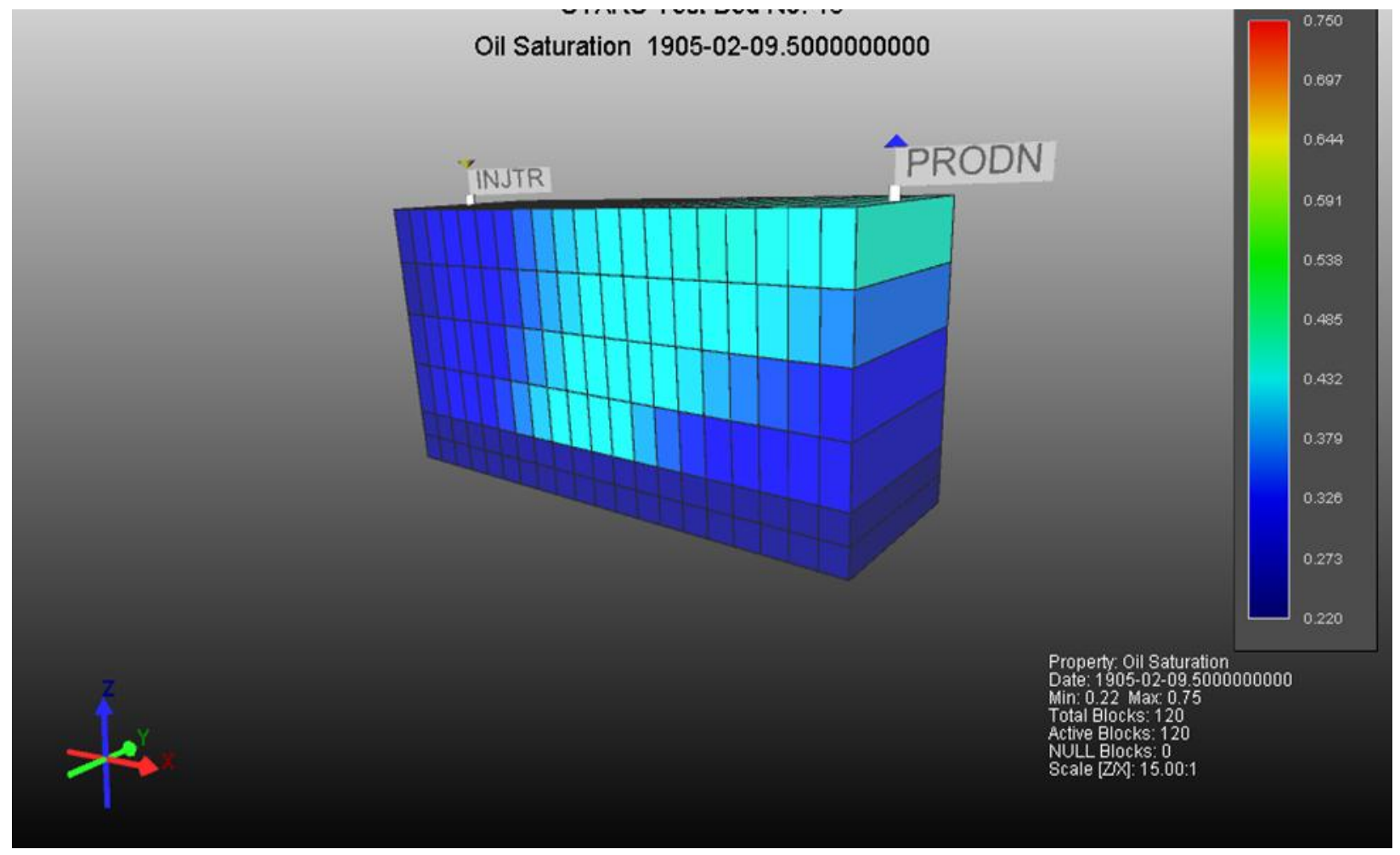

Figure 13 Oil Saturation - Xanthan Model (Final)

\section{Results \& Conclusion}

Sensitivity studies are carried out on the same reservoir model using gel, water, xanthan and PAM, to understand and illustrate the significance of reservoir and operational parameters in each process. Table. $\mathbf{1} \mathbf{\&} \mathbf{2}$ display the input components as well as input parameters for the simulation model. Fig. 10 displays the heterogen reservoir simulation grid. Fig 11 - Fig. 13 illustrate the parameter of oil saturation final of three cases.

Fig 14 shows the comparison of cumulative oil production for three cases. The highest cumulative oil earned by PAM injection, followed by Gel and Xanthan within the same period of time (1500 days). 


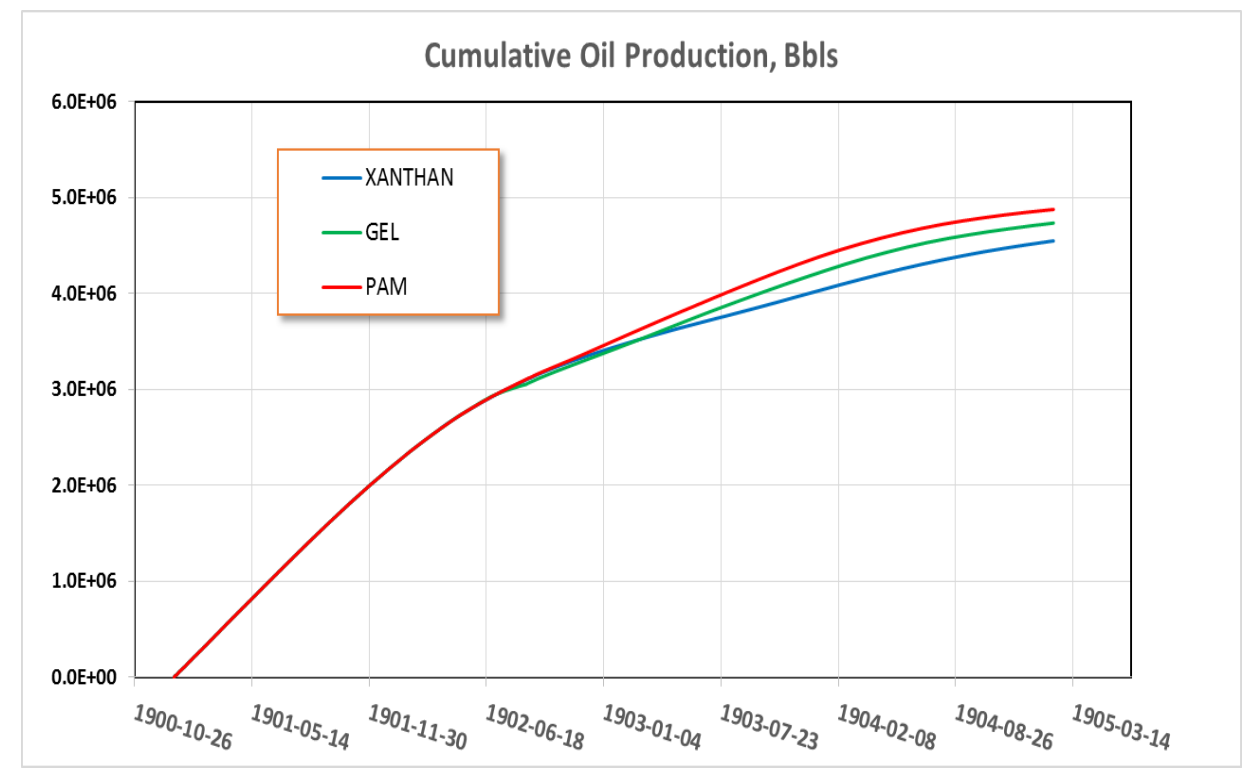

Figure 14 Cumulative Oil Production for three cases

In order to investigate the critical parameter which have more influences into oil production, an optimization work has been conducted through commercial tools. By putting several parameters that assumed can give any impact to cumulative production, multiple runs are conducted to get the ultimate values.

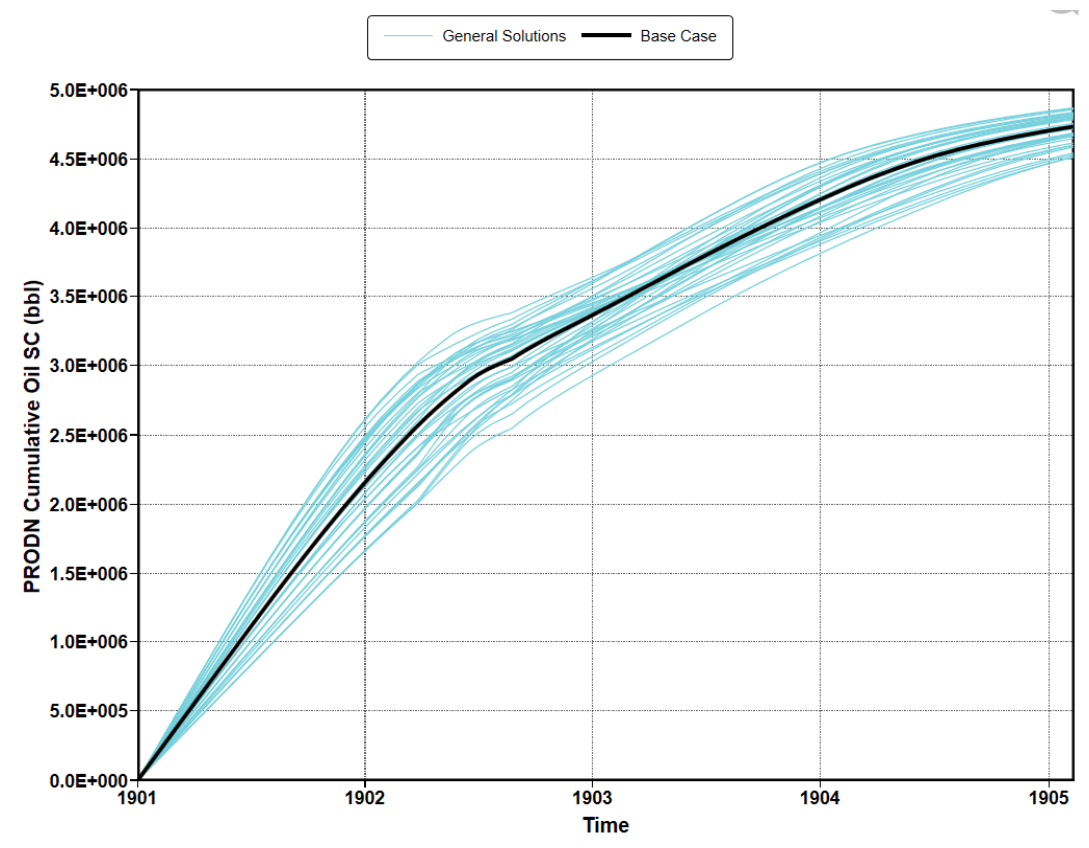

Figure 15 Gel Model effect estimates 


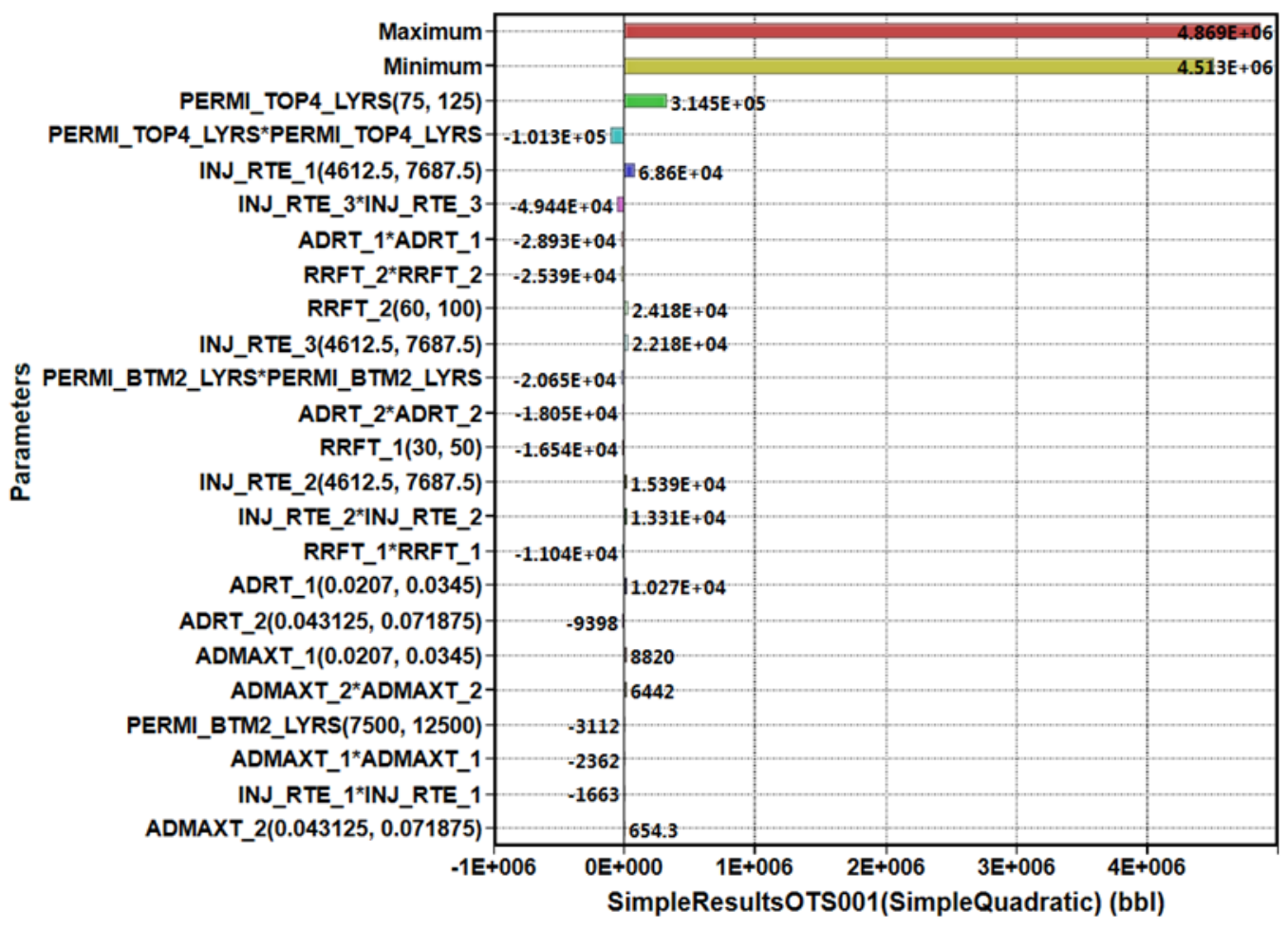

Figure 16 Gel Model tornado diagram

Fig. 15 shows the base case of Gel model and general solution of tens runs, meanwhile Fig. 16 shows the maximum and minimum cumulative oil values as defined as objective functions. It displays parameter permeability of layers 4 that driving the result mostly and injection rate 1 as a controllable parameter to increase the oil production.

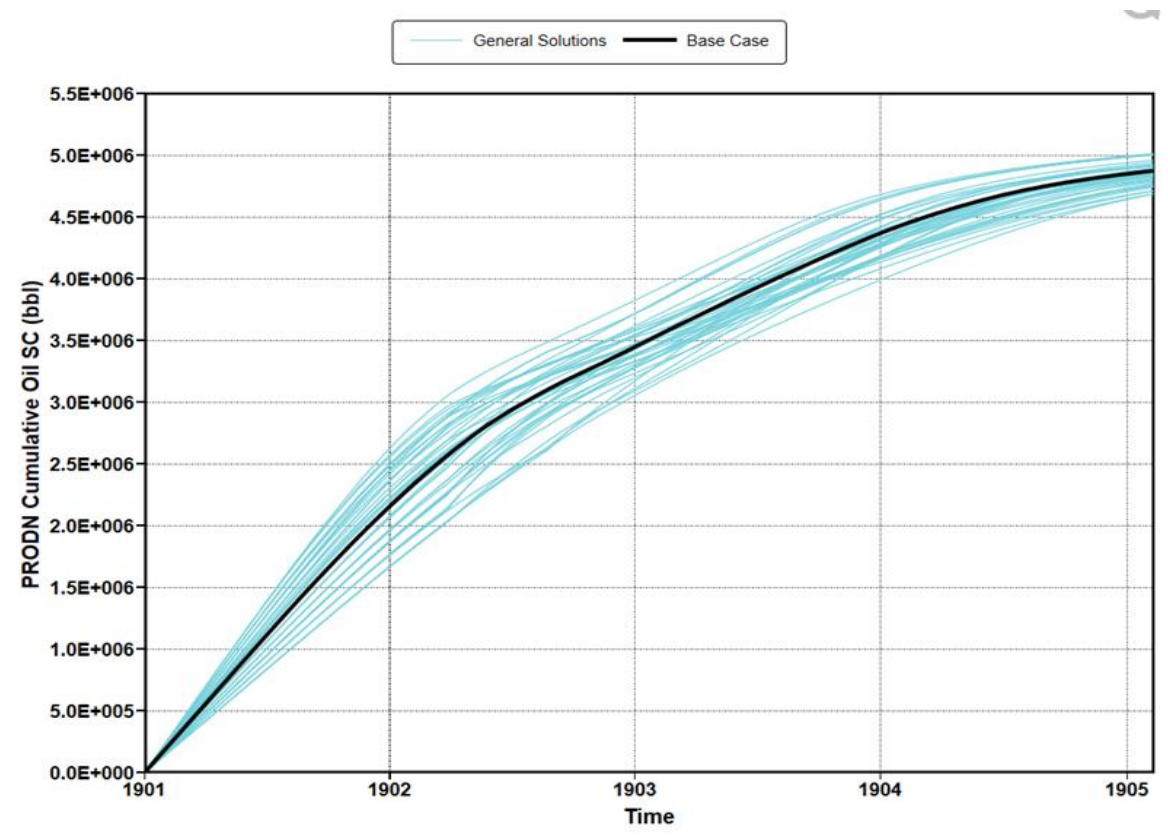


Figure 17 PAM Model effect estimates

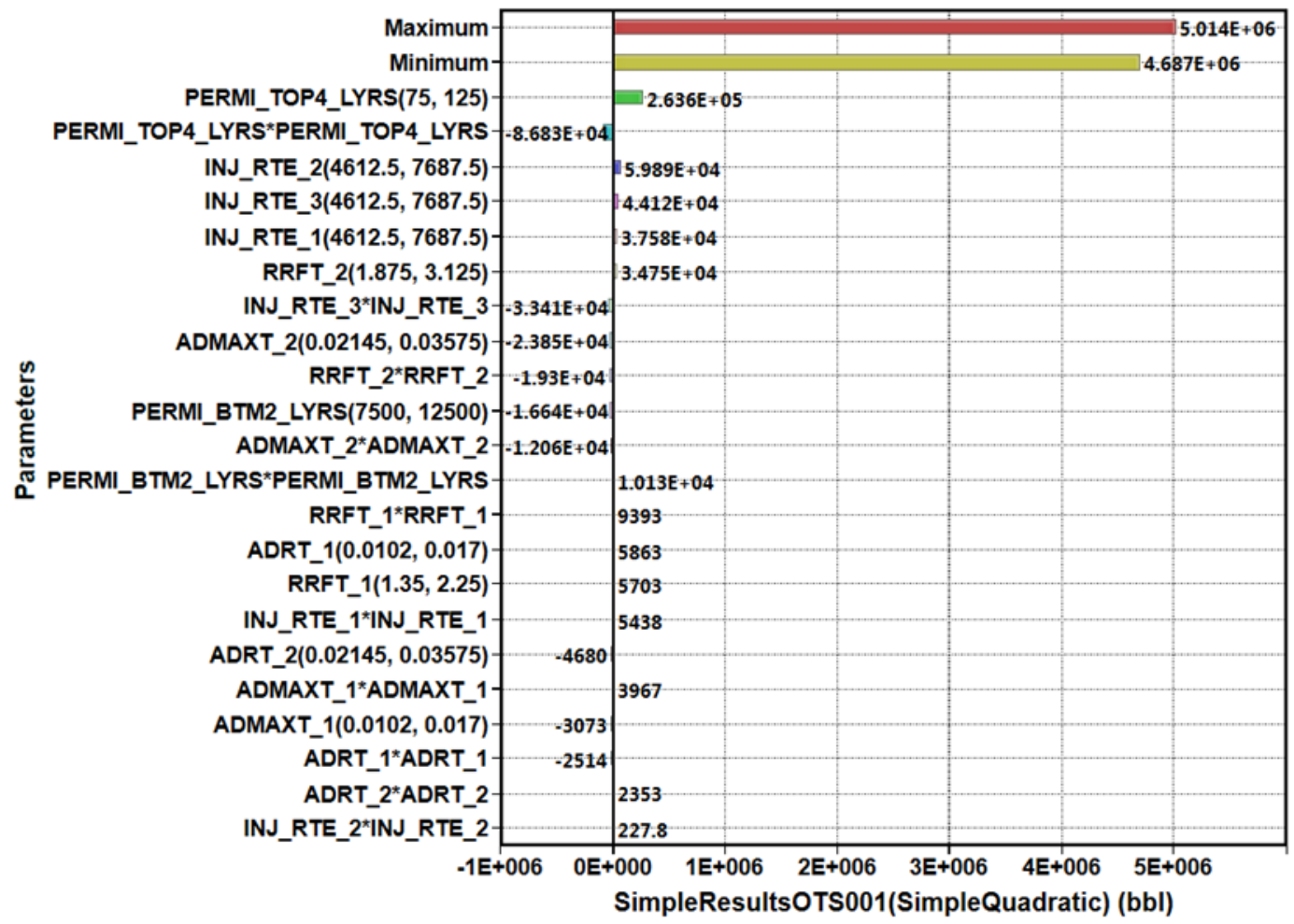

Figure 18 PAM Model Model tornado diagram

Fig. 17 shows the base case of Gel model and general solution of tens runs, meanwhile Fig. 18 displays parameter permeability of layers 4 that driving the result mostly and injection rate $2 \& 3$ as controllable parameter to increase the oil withdrawal.

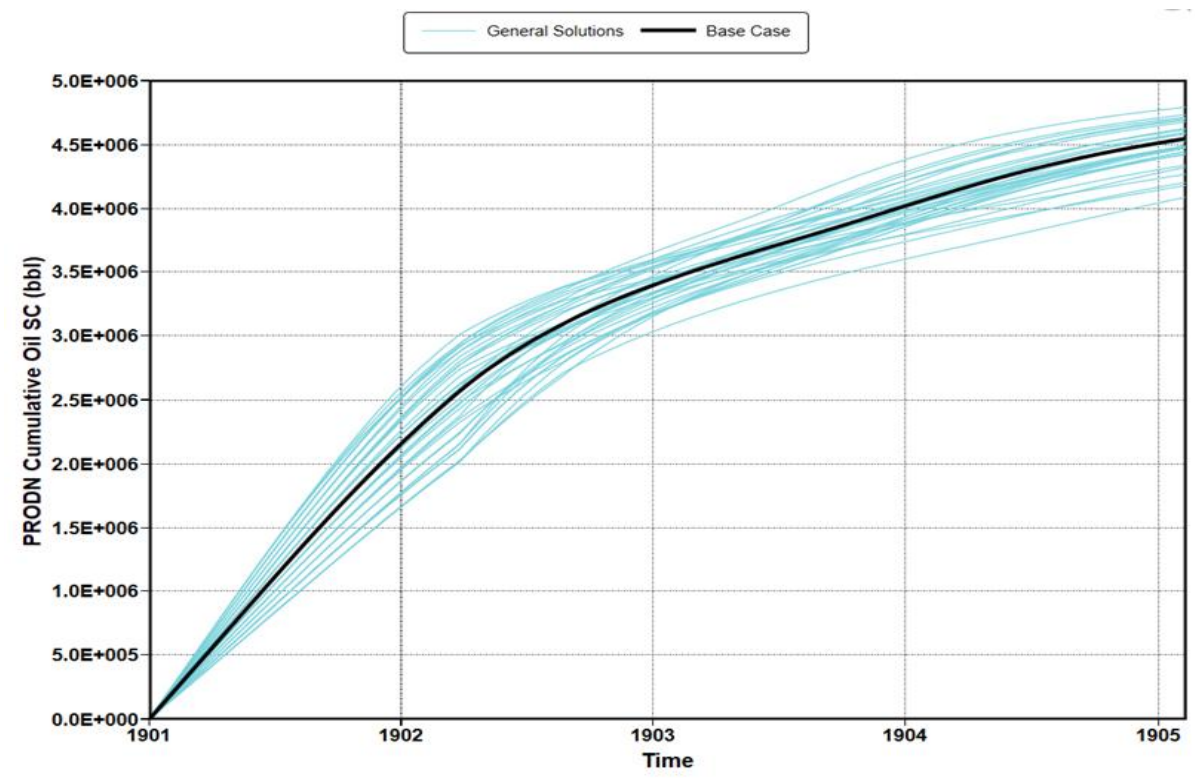

Figure 19 Xanthan Model effect estimates 


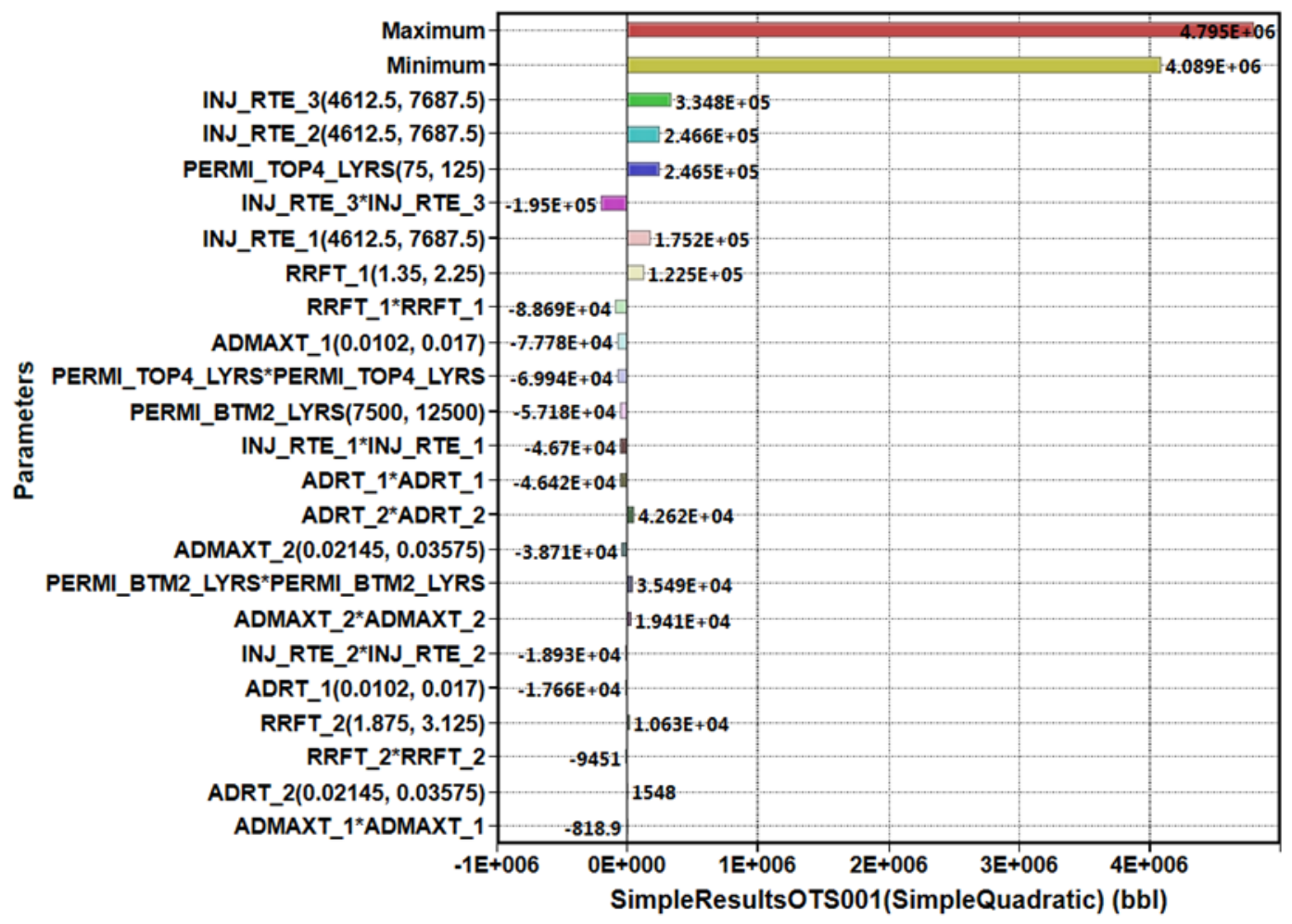

Figure 20 Xanthan Model tornado diagram

Fig. 19 shows the base case of Gel model and general solution of tens runs, meanwhile Fig. 20 exhibits parameter injection rate 3 that leading the result mostly and followed by injection rate $2 \& 1$. All of them are the controllable parameters to increase the oil production.

The final results show respectively, the highest recovery is PAM with cumulative oil in range 5,014x106

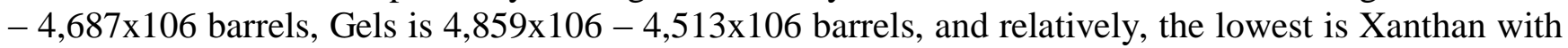
$4,795 \times 106-4,089 \times 106$ barrels.

Although different models may lead to different results and interpretations, it is observed that there is a significant improvement in recovery with the use of PAM, Gels and Xanthan. Operational parameters, such as, injection rate has a significant impact on the cumulative oil recovery. Injection rate 1 is pure water injection, injection rate 2 is injection with the material used, and injection rate 3 is the one that follows injection of the material. In this sense, it might be obvious that injection rate 2 may play a significant role in the recovery, but it is seen that injection rates 1 and 3 are also have significant importance in the results. Like in every process, having operational parameters with more significance on the results is useful as we have control of operational parameters as compared to reservoir parameters. This study by using a synthetic but realistic model aims to illustrate the significance of operational and reservoir parameters to serve as a simple example in each process.

Another interesting from this modeling is adsorption in deep penetration. Gel model (Fig 21) has the highest adsorption mass density in 80ft deep region, and 60-80ft for adsoption fluid component within pressure decline range 4220 psi to 4150psi. Meanwhile, PAM model (Fig 22) has both highest within deep penetration range $60-80 \mathrm{ft}$ in pressure value $4230 \mathrm{psi}$. 


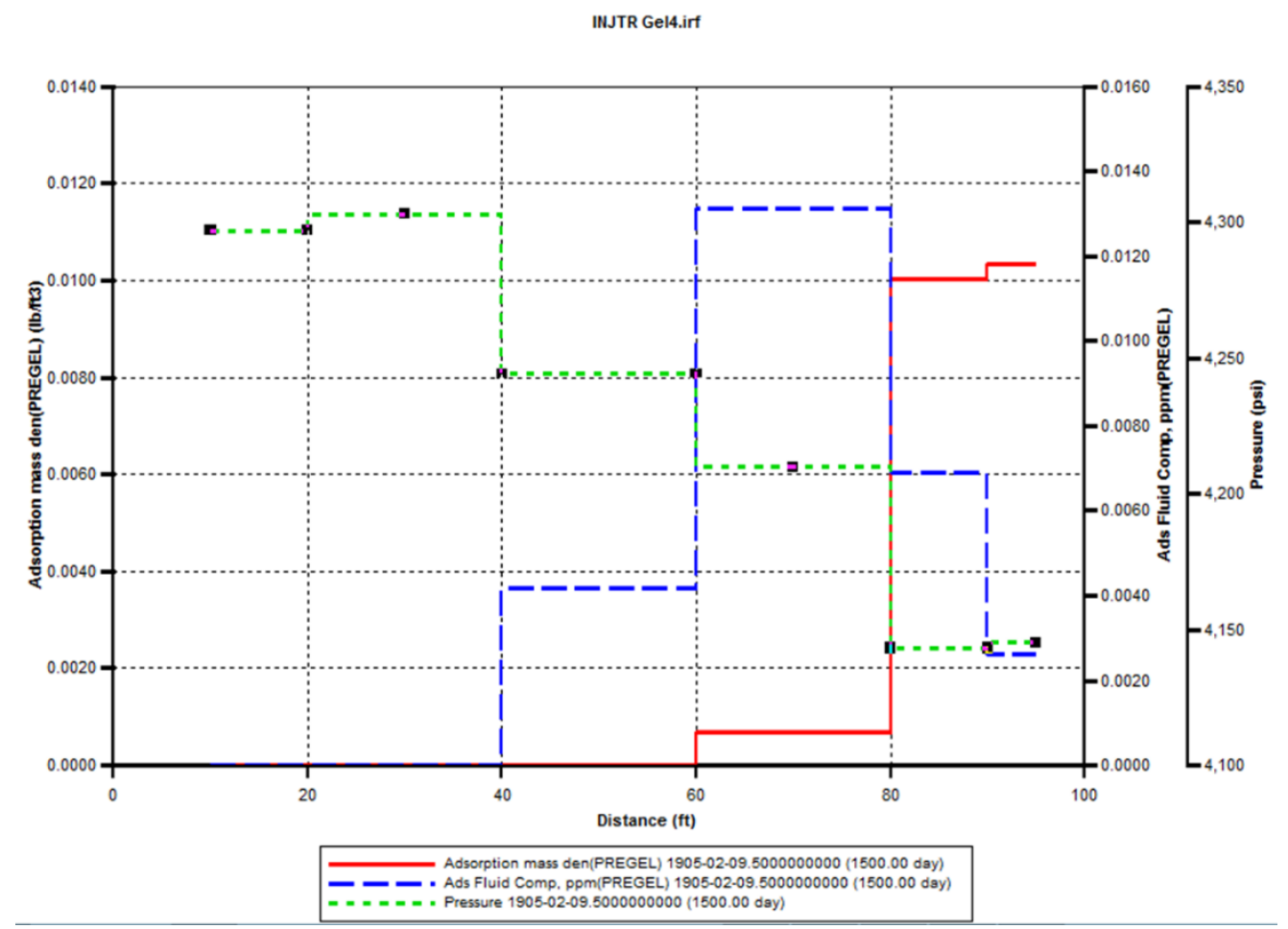

Figure 21 Adsorption phenomenon in deep penetration for Gel Model

INJTR pam4.irf

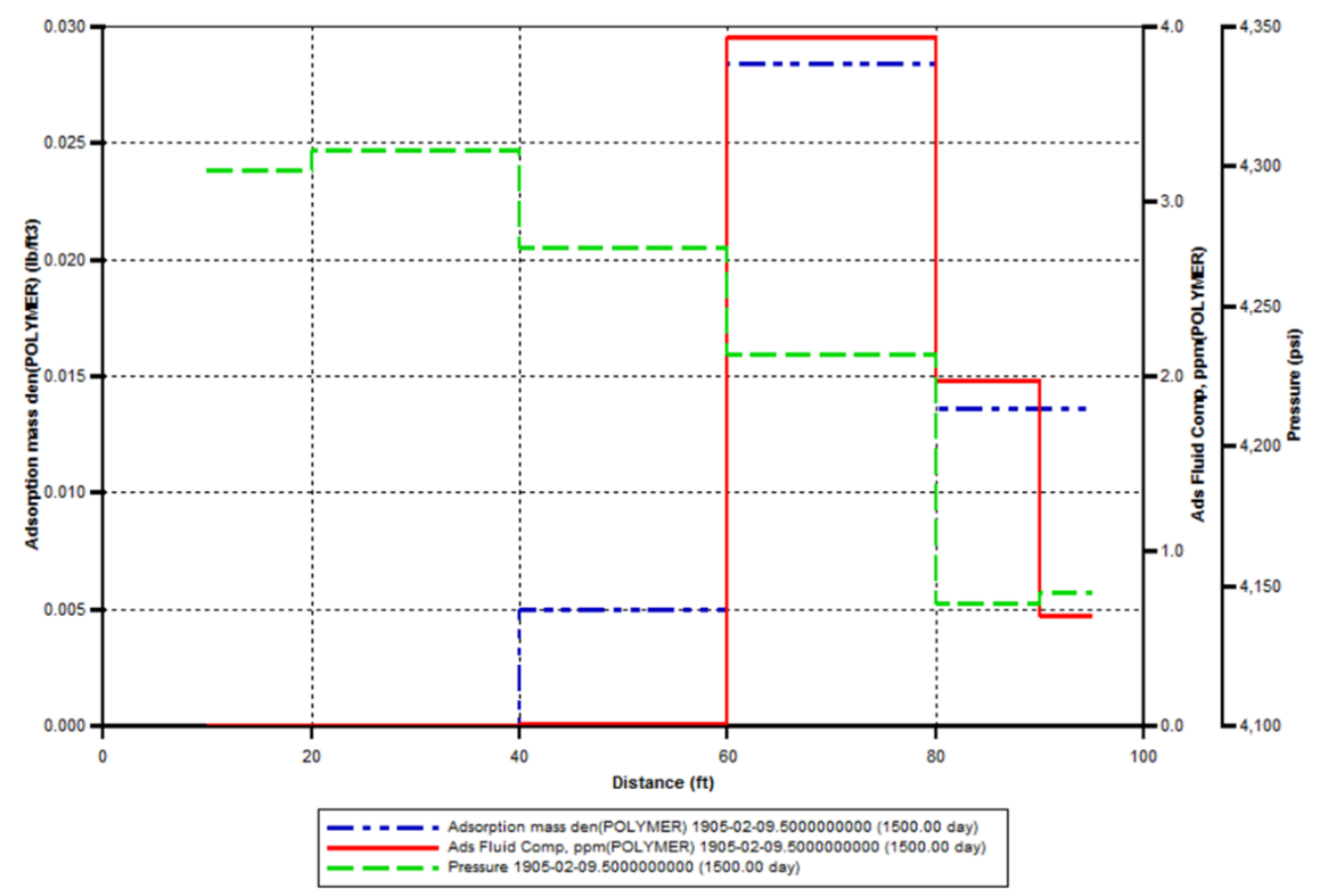

Figure 22 Adsorption phenomenon in deep penetration in PAM Model 


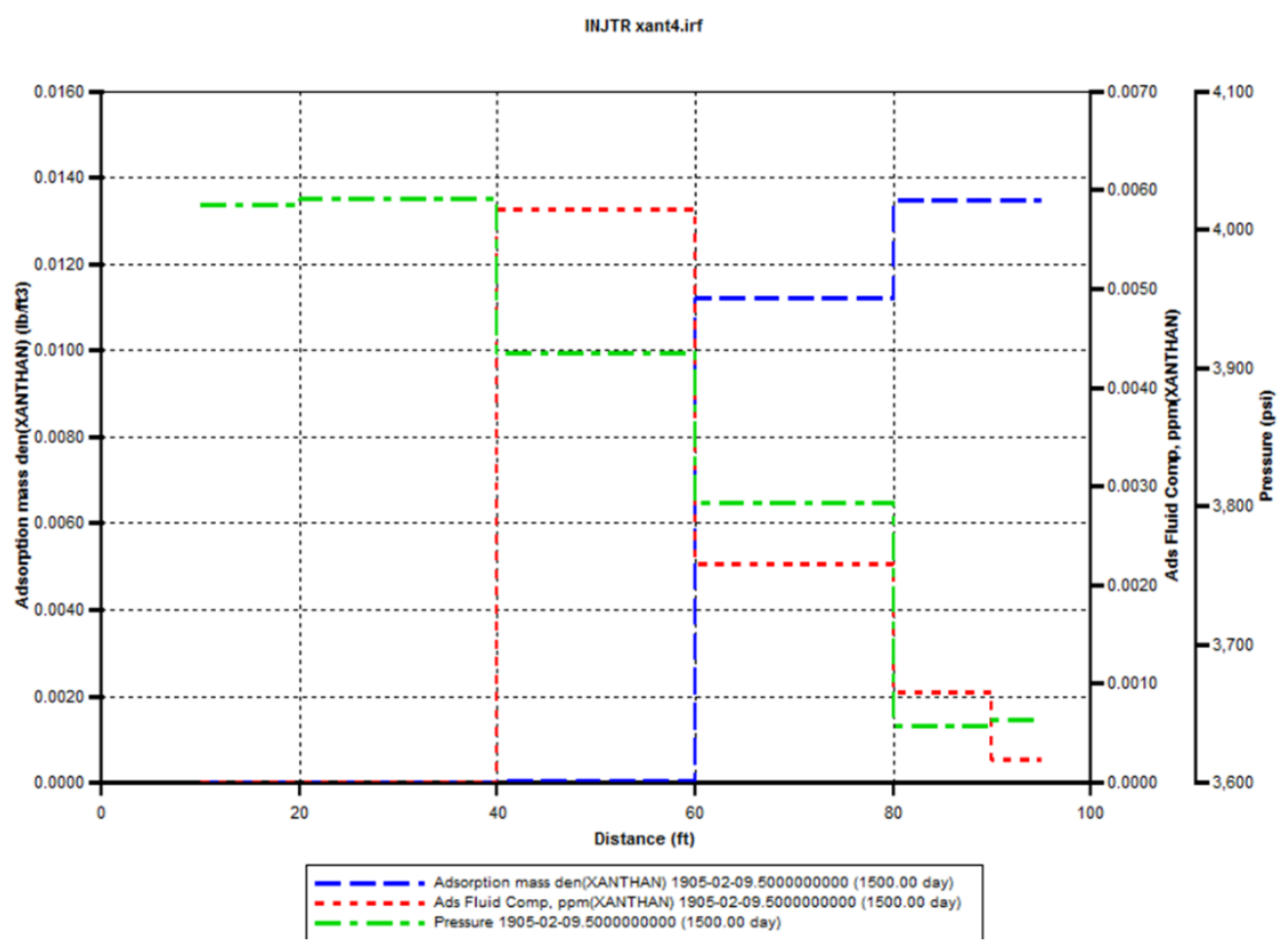

Figure 23 Adsoption phenomenon in deep penetration for Xanthan Model

Xanthan model (Fig 23) shows the highest adsorption mass density in 80ft deep region, while adsoption fluid component within 40-60ft region in pressure decline range 3850 psi to 3650psi. Anyhow, all cases show the blocking effect within 20-40ft region by increasing pressure up to 4300psi for Gel and PAM cases, and up to 4000psi for Xanthan case.

This study has not considered the economics of the process. Future work aims to involve this important component of these processes as cost, which is a very significant part of such enhanced recovery methods. Future work may include the use of a real-field models and an NPV-based approach to compare the advantages and disadvantages of each process.

\section{Acknowledgements}

Authors thank Rafflesia Energy and Aera Energy LLC (a Shell-ExxonMobil Affiliate)

\section{References}

Abidina A. Z., Puspasaria T., Nugroho W. W., (2012), Polymers for Enhanced Oil Recovery Technology, Procedia Chemistry, 4:11-16, Indonesia

Chen Q., Wang Y., Lu Z., Feng Y., (2013), Thermoviscosifying Polymer Used for Enhanced Oil Recovery: Rheological Behaviors and Core Flooding Test, Polym. Bull., , 70:391-401

Sorbie K.S. (1991), Polymer-Improved Oil Recovery, Springer Science+Business Medai, LLC, New York

Sheng J. J., Leonhardt B., Azri N., Status of Polymer Flooding Technology, March 2015, Journal of Canadian Petroleum Technology 
Wever, D.A.Z., Picchioni, F., Broekhuis A.A. (2011), Polymers for enhanced oil recovery: A paradigm for structure-property relationship in aqueous solution, Progress in Polymer Science 36, 15581628

Taylor K. C., Nasr-El-Din H. (1998), Water-soluble Hydropobically Associating Polymers for Improved Oil Recovery: A Literature Review, Journal of Petroleum Science and Engineering, Vol. 19, Issues 3-4, (March), Pages 265-280

Sheng J. (2011), Modern Chemical Enhanced Oil Recovery-Theory and Practice

Cook, B. C. (2003), Characterization of Comb Polymer Kypam for Enhanced Oil Recovery, Dissertation.

Vroman I., Tighzert L. (2009), Biodegradable Polymers, Materials, 2, 307-344, France

Al-Sulaimani H., Joshi S., Al-Wahaibi Y., Al-Bahry S., Elshafie A., Al-Bemani A. (2011), Microbial Biotechnology for Enhancing Oil Recovery, Society of Applied Biotechnology, India

Sen R. (2008), Biotechnology in Petroleum Recovery: The Microbial EOR, Progress in Energy and Combustion Science, 34: 714-724

Survase A. A., Saudagar P. S., Bajaj I. B., Singhal R. S. (2007), Scleroglucan: Fermentative Production, Downstream Processing and Application, Food Technol. Biotechnol. 45 (2) 107-118

Sang Q., Li Y., Li Z., Dong M. (2014), Enhanced Oil Recovery by Branched-Preformed Particle Gel Injection in Parallel-Sandpack Models, Fuel 136 295-306

Wang D. (2013), Polymer Flooding Practice in Daqing, Enhanced Oil Recovery Field Studies, Book Chapter 4

Liang J., Seright R. S. (1997), Further Investigations of Why Gels Reduce Water Permeability More Than Oil Permeability, SPE Production and Facilities, (November)

Tongwa P., Bai B. (2014), Degradable Nanocomposite Preformed Particle Gel for Chemical Enhanced Oil Recovery Applications, Journal of Petroleum Science and Engineering 124 35-45

Liao J. (2014), Gel treatment field application survey for water shut off in production wells, Missouri University of Science and Technology, MS Dissertation, Fall

T. Ahmed. (2001), Reservoir Engineering Handbook, Gulf Professional Publishing, Texas, pp.256-278

A. Satter, G.Iqbal \& J. Buchwalter. (2008), Practical Enhanced Reservoir Engineering, PennWell Corporation, Oklahoma, pp.62-72

Zhang, M., Yilmaz, T., Boztas, A.O., Karakuzu, O., Bang, W.Y., Yegin, Y., Luo, Z., Lenox, M., Cisneros-Zevallos, L. and Akbulut, M. (2016). A multifunctional nanoparticulate theranostic system with simultaneous chemotherapeutic, photothermal therapeutic, and MRI contrast capabilities. RSC Advances, 6(33), pp.27798-27806.

Zhang, M., Soto-Rodríguez, J., Chen, I.C. and Akbulut, M., 2013. Adsorption and removal dynamics of polymeric micellar nanocarriers loaded with a therapeutic agent on silica surfaces. Soft Matter, 9(42), pp.10155-10164. 
Zhang, M. and Akbulut, M., 2011. Adsorption, desorption, and removal of polymeric nanomedicine on and from cellulose surfaces: effect of size. Langmuir, 27(20), pp.12550-12559.

Cziple F. A., Marques A. J. V., Biopolymers versus Synthetic Polymers, Anul 15, NR. 1, 2008, ISSN $1453-7397$

Yegin, Y., Perez-Lewis, K.L., Zhang, M., Akbulut, M. and Taylor, T.M., 2016. Development and characterization of geraniol-loaded polymeric nanoparticles with antimicrobial activity against foodborne bacterial pathogens. Journal of Food Engineering, 170, pp.64-71.

Orts W. J., Roa-Espinosa A., Sojka R. E., Glenn G. M., Imam S. H., Erlacher K., Pedersen J. S. (2007). Use of Synthetic Polymers and Biopolymers for Soil Stabilization in Agricultural, Construction, and Military Applications, Journal of Materials in Civil Enginering, 19(1), 58-66

Wever D. A. Z., Picchioni F., Broekhuis A. A. (2011). Polymers for Enhanced Oil Recovery: A Paradigm for Structure-Property Relationship in Aqueous Solution, Progress in Polymer Science, 36, 1558-1628

Hamed S. B., Belhadri M. (2009). Rheological Properties of Biopolymers Drilling Fluids, Journal of Petroleum Science and Engineering, 67: 84-90

Woodrow J. E., Seiber J. N. and Miller G. C. (2008). Acrylamide Release Resulting from Sunlight Irradiation of Aqueous Polyacrylamide/Iron Mixtures. Journal of Agricultural and Food Chemistry. 56 (8): 2773-2779.

Sisnaiske, J., Hausherr, V., Krug, A. K., Zimmer, B., Hengstler, J. G., Leist, M., \& van Thriel, C. (2014), Acrylamide alters neurotransmitter induced calcium responses in murine ESC-derived and primary neurons, Neurotoxicology, 43, 117-126.

Kalia, S. and Avérous, L. (2011), Biopolymers: biomedical and environmental applications (Vol. 70). John Wiley \& Sons.

Elancheziyan S. SD., Sivasurian N., Meenakshi S. (2014), Recovery of oil from oil-in-water emulsion using biopolymers by adsorptive method, International Journal of Biological Macromolecules, India, 70 399-407

$\mathrm{Hu}, \mathrm{X}$. and Gong, X. (2016), A new route to fabricate biocompatible hydrogels with controlled drug delivery behavior. Journal of colloid and interface science, 470, pp.62-70.

Temizel, C, Putra, D, Anggraini, H, Moreno, R. (2017), Economic Comparison of Hydrocarbon Recovery under Injection of Different Polymers, This paper was presented the SPE/IATMI Asia Pacific Oil \& Gas Conference and Exhibition held in October 17-19, Bali, Indonesia, SPE186414-MS

L.R.Zeron (2012), “Introduction to Enhanced Oil Recovery (EOR) Processes and Bioremediation of Oil-Contaminated Sites", InTech Europe, pp.1-36

Kirk-Othmers (2013), “Kirk-Othmer Chemical Technology of Cosmetics provides information on key topics related to cosmetic and personal care products including natural products, ingredients, formulation technology, and regularoy aspects", John Wiley \& Son Inc, pp.606 